\title{
Evolution of Neolithic site distribution (9.0-4.0 ka BP) in Anhui, East China
}

\author{
WU Li ${ }^{1,2}$, SUN Xiaoling ${ }^{1}$, SUN Wei ${ }^{3},{ }^{*}$ ZHU Cheng ${ }^{3}$, ZHU Tongxin ${ }^{4}$, LU Shuguang ${ }^{1}$, \\ ZHOU Hui ${ }^{1}$, GUO Qingchun ${ }^{5}$, GUAN Houchun ${ }^{6}$, XIE Wei ${ }^{1}$, KE Rui ${ }^{1}$, LIN Guiping ${ }^{1}$ \\ 1. Provincial Key Laboratory of Earth Surface Processes and Regional Response in the Yangtze-Huaihe River \\ Basin, School of Geography and Tourism, Anhui Normal University, Wuhu 241002, Anhui, China; \\ 2. State Key Laboratory of Loess and Quaternary Geology, Institute of Earth Environment, CAS, Xi'an 710061, \\ China; \\ 3. School of Geography and Ocean Science, Nanjing University, Nanjing 210023, China; \\ 4. Department of Geography, University of Minnesota Duluth, MN 55812, USA; \\ 5. School of Environment and Planning, Liaocheng University, Liaocheng 252000, Shandong, China; \\ 6. Geological Survey of Anhui Province, Hefei 230001, China
}

\begin{abstract}
Based on archaeological surveys of Neolithic cultural development and GIS spatial analysis, this study reproduced the main characteristics of temporal distribution and settlement selection of the sites from the Neolithic Age in Anhui and identified a relationship between environmental evolution and human activity. The results show that altitude, slope direction, and slope gradient were consistent among the settlements at different stages of the Neolithic Age in Anhui, and the sites were mostly distributed in hilly and plain areas on southeast- or south-facing slopes of low gradients close to rivers. We determined that early Neolithic Age (9.0-7.0 ka BP) sites were scattered in small numbers and likely had little cultural exchange with communities of other provinces. The environmental characteristics of various regions in Anhui indicated that the climate was warm and humid with extensive water distribution. The sites of the mid Neolithic Age (7.0-5.0 ka BP) increased rapidly with wide distribution. They were mainly distributed in the plain area north of the Huaihe River and the southwestern areas of Anhui. In the mid Neolithic Age, the warm and humid climate gradually dried, and our ancestors slowly developed cultural exchanges. The largest number of sites existed during the late Neolithic Age (5.0-4.0 ka BP), and were distributed throughout the province. During this period, the overall climate was relatively dry, but humans could still obtain water and other resources through migration. The relatively benign climate facilitated cultural interaction and exchange, which increased during this time, and the Wanjiang culture
\end{abstract}

Received: 2019-09-05 Accepted: 2020-04-30

Foundation: National Natural Science Foundation of China, No.41771221, No.41571179; Foundation of State Key Laboratory of Loess and Quaternary Geology, Institute of Earth Environment, Chinese Academy of Sciences, No.SKLLQG1851; China Postdoctoral Science Foundation, No.2018M632403; National Key Technologies R\&D Program, No.2016YFA0600501; National Innovation Training Program for College Students, No.201810370207

Author: Wu Li (1985-), Professor, specialized in environmental evolution and geoarchaeology. E-mail: jedi-wuli@163.com

"Corresponding author: Zhu Cheng (1954-), Professor, specialized in environmental evolution and geoarchaeology.

E-mail: zhuchengnj@126.com 
matured. We also determined that as early civilization evolved, cultures in different regions responded differently to environmental changes. In humid subtropical regions, especially in low-lying plains and areas beside lakes, rivers, and coastal areas, the relatively dry climate in the late period of the middle Holocene, prefaced by a period of high humidity, was conducive to the development of human culture. The evidence from the Neolithic settlements in Anhui therefore reflects this subtropical man-land relationship between cultural development and environmental conditions.

Keywords: Neolithic; spatial-temporal distribution pattern; man-land relationship; environmental archaeology; Anhui, East China

\section{Introduction}

The history of human life can be summarized as developing ways to adapt to the environment around them (Li et al., 2013; Roberts, 2014; Schirrmacher et al., 2020). Understanding how to live successfully within our environment is still among the most pressing challenges facing society (Redman et al., 2004; NRC, 2010; IPCC Core Writing Team, 2014). Attempts to interpret the relationship between prehistoric humans, our ancestors' settlements, the development of primitive civilization, and the natural environment, can be traced back to the 1950s (Willey, 1953; Haggett, 1965; Trigger, 1967). These interpretations allow us to use the past to further our understanding of the dynamic and complex system of human-nature interaction. It is rooted in classic Chinese philosophy that man is an integral part of nature. Therefore, knowing how to preserve the harmony between nature and humans has always been an important domain in geographical science ( $\mathrm{Fu}$ and Pan, 2016; Leng et al., 2017). Recently, discussions surrounding the variable patterns of human prehistoric sites and their geographic context in China have begun to focus on the relationship between the spatial-temporal distribution of settlement sites and the geographical environment (Liu and Feng, 2012; Li et al., 2013; Chen et al., 2015; Wang et al., 2015; Putzer et al., 2016; Weiberg et al., 2016; Dutt et al., 2019; Lu et al., 2019). Previous studies have primarily focused on the Yellow River Basin (Dong et al., 2013; Guo et al., 2013; Wagner et al., 2013; Li et al., 2015), a delta area in the lower reaches, and the Jianghan-Dongting Plain, located in the middle reaches of the Yangtze River (Chen et al., 2008; Deng et al., 2009; Wu et al., 2014a, 2014b, 2018; Zhao and Mo, 2020). Consequently, there has been little research on the south-north transition belt in the eastern monsoon region of China (e.g. Anhui). Studies in Anhui have been conducted only in either the Huaihe River Basin (Huang et al., 2006) or the Chaohu Plain (Wu et al., 2010). There is a lack of comprehensive environmental archaeologic research on past man-land relationships over a large time scale across Anhui Province. During the Neolithic Age, Anhui was the central region where Haidai, Jianghan, Taihu, and Zhongyuan cultural circles overlapped (Wu and Liu, 2004; Su, 2009). It connected the cultures in all cardinal directions and was a core area for major cultural exchange and collision in the surrounding region. Therefore, the development of Neolithic culture in Anhui has special significance in the origin of early Chinese civilization. Regarding the entire developmental process of Neolithic culture, research on the evolution of Neolithic site distribution and man-land relationships in Anhui can provide a theoretical basis for research on the development, communication processes, and laws of China's Neolithic culture. In addition, this research will help reveal the evolution of cultural exchange during the Anhui Neolithic 
Age and the rules of man-land interactions in the regional system.

\section{Geographic setting}

Anhui, located in East Asia $\left(29.4^{\circ}-34.6^{\circ} \mathrm{N}\right.$ and $\left.114.9^{\circ}-119.8^{\circ} \mathrm{E}\right)$, is a near sea inland province of East China. Its prominent rivers belong to three major river systems, the Yangtze, Huaihe, and Xin'an rivers. The land is mainly comprised of plains, hills, and low mountains (CCCAP, 1999). The major geomorphologic units include the Huaibei Plain, formed by the alluviation of the Huaihe River with its tributaries, and the Wanjiang Plain along the lower reaches of the Yangtze River, as well as the Jianghuai hills, Mt. Dabie, and mountains in the south of Anhui ( $\mathrm{Li}$ et al., 2010). Across the plains, the average altitude is $20-40 \mathrm{~m}$, with a minimum altitude below $10 \mathrm{~m}$. In the Jianghuai hills, the average altitude is $300-1000 \mathrm{~m}$, and the Lotus Peak of Mt. Huangshan, the highest point in Anhui, has an altitude of 1864.8 $\mathrm{m}$. The region's climate is attributed to the transitional belt between the warm temperate and subtropical zones (IGSMAP, 2017). The Qinling Mountains-Huaihe River Line across Anhui divides North and South China (Sun, 2013; Wu et al., 2016). The mean annual temperature ranges from 14 to $17^{\circ} \mathrm{C}$ with distinct seasonal changes. The annual precipitation is approximately $770-1670 \mathrm{~mm}$, with more rain in the south. Precipitation is largely concentrated in June to September, with great annual variations (Li et al., 2010). The province has rich and varied biological resources, including a deciduous broadleaved forest in the north of the Huaihe River, and a deciduous-evergreen broadleaved mixed forest in the south of the river (Zhang et al., 2010).

\section{Materials and methods}

The cultural sequence of Neolithic sites in Anhui was classified into different periods based on: (1) the overlying relationship of the Neolithic archaeological site strata, (2) the characteristics of unearthed relics, such as stone tools and pottery (CCCAP, 1998; Zhang, 2004; Zhu et al., 2005; Huang et al., 2006; Su, 2008; Wu et al., 2010; Zhang et al, 2010; Sun, 2013; Shuo, 2015; Zhu et al., 2015), (3) ${ }^{14} \mathrm{C}$ dates of the archaeological sites (Chorography Compiling Commission of Anhui Province, 1998; Wu et al., 2012a, 2012b; Sun, 2013; Zhu et al., 2013, 2015; SACH, 2014; Wang, 2015), and (4) the Anhui Chorography $\cdot$ Relic and An Atlas of Chinese Cultural Relics · Anhui (CCCAP, 1998; State Administration of Cultural Heritage, 2014). It was then further divided into three periods: the early (9.0-7.0 ka BP), mid (7.0-5.0 ka BP), and late Neolithic Age (5.0-4.0 ka BP). By combining the archaeological data and local chronicles (http://www.ahdfz.gov.cn/) with investigations of over 60 sites and their regional landforms, we counted a total of 367 Neolithic sites in Anhui, composed of 12 early, $87 \mathrm{mid}$, and 268 late Neolithic sites. Meanwhile, attribute data of the sites were collected, including the site name, location, and age, as well as its cultural stage.

Three essential Neolithic site distribution maps were included in this study: an SRTM digital elevation model (DEM) with a resolution of $90 \mathrm{~m} \times 90 \mathrm{~m}$, a topographic map, and a drainage map. The dataset was provided by the International Scientific Data Service Platform of Computer Network Information Center, Chinese Academy of Sciences. The positional data of the Neolithic sites were extracted from An Atlas of Chinese Cultural Rel- 
ics Anhui (SACH, 2014). All of the Neolithic cultural sites were plotted on a relief map, i.e. a Chinese vector electronic map, using MapInfo Professional 7.8 software to create a point layer that identified the number, name, archaeological culture, and position of each site. The relief map was then transformed into an ArcGIS shapefile format to obtain the layers of cities, rivers, reservoirs, lakes, and the basic point layer under a workspace. While in this format, the DEM data was added. Furthermore, ArcGIS data extraction tools were utilized to obtain the longitude, latitude, and altitude information of the sites and to add the property charts, meaning that every layer in the given workspace was edited (e.g. adjusting lines and symbols, setting colours and adding map elements, such as a legend, scale and compass) to create spatial-temporal distribution maps of the Neolithic cultural sites in different periods (Figures 1-3). Given that there has been little change in the topography and river systems since the Holocene epoch in Anhui (Lu et al., 1992; Chorography Compiling Commission of Anhui Province, 1999; Huang et al., 2006; Li et al., 2010; Wu et al., 2010, 2016; Zhang et al., 2010; Wang et al., 2012; Sun, 2013), we evaluated the effects of altitude, slope direction, and slope gradient on the spatial-temporal distribution patterns of the Neolithic cultural sites in different periods using ArcGIS spatial analysis tools. Furthermore, we examined the impacts of regional paleoenvironmental evolution and the development of prehistoric society. Finally, we comprehensively discussed the characteristics of man-land relationships based on the evolution of site distribution patterns revealed in our research.

\section{Results and analysis}

From the macroscopic comparison of the early, mid, and late Neolithic site distribution in Anhui, we found that in the early Neolithic Age, the number of sites was small, and those sites were distributed intensively in separate areas. In the mid Neolithic Age, the number of sites increased greatly in the centre of the Huaibei Plain and the southwestern Anhui, but were distributed scatteredly and increased at a slower rate in other parts of the province. In the late Neolithic Age, the number of sites increased rapidly and their distribution ranged throughout the whole province of Anhui. We also learned that the early Neolithic sites were mainly separate cradles, and on that developed basis, the distribution of the mid and late Neolithic sites gradually expanded and extended to the surrounding areas. In addition, the sites were mostly distributed in places of lower altitude, such as plain and hilly areas.

\subsection{Altitude distribution}

Table 1 and Figure 1 show that, in the early Neolithic Age, 11 of the 12 sites existed below an altitude of $50 \mathrm{~m}$ and only 1 , the Gouting site, was located above $100 \mathrm{~m}$ in south of Anhui. This indicates that our ancestors mainly lived in the flat hilly plain areas in this period. In the mid Neolithic Age, sites located at altitudes less than $50 \mathrm{~m}$ continued to account for a large proportion (Table 1 and Figure 2). Though this time had warm and humid climate conditions due to the Holocene Megathermal, people still chose to live at lower altitudes. This could be because the widely distributed soil in the northern plain was rich in phosphorus and potassium, providing a natural basis for crop growth, and was therefore beneficial to human survival and development. The number of late Neolithic sites grew rapidly compared with 


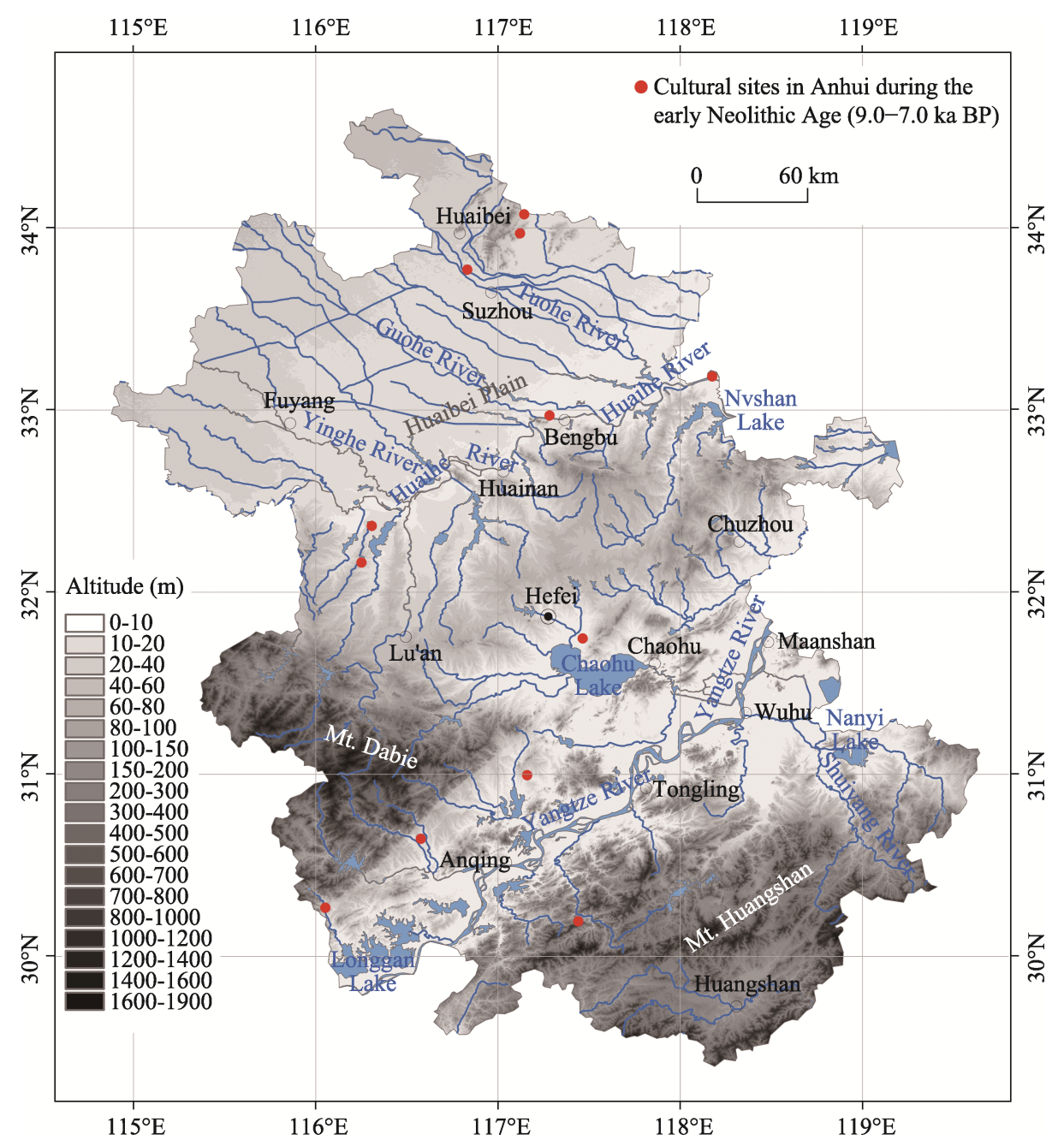

Figure 1 Distribution of cultural sites in Anhui during the early Neolithic Age (9.0-7.0 ka BP)

the middle Neolithic Age. Those existing below $50 \mathrm{~m}$ doubled, but the proportion declined (Table 1 and Figure 3). At this time, the climate might have been drier as we identified drops in the sea level and river erosion datums. This led humans to move to low altitudes, which were close to rivers, to meet their water needs. However, not all the sites were at lower altitudes, which may be due to settlements developing rapidly at that time, and increasing the competition between settlements for natural resources. In order to explore new living territory, some of our ancestors had to move to higher altitudes to obtain new living conditions.

\subsection{Slope direction}

Based on $0-360^{\circ}$ azimuth values, slope directions were classified into a flat orientation and eight directions: north $\left(0-22.5^{\circ}\right.$ and $\left.337.5^{\circ}-360^{\circ}\right)$, northeast $\left(22.5^{\circ}-67.5^{\circ}\right)$, east $\left(67.5^{\circ}-\right.$ $\left.112.5^{\circ}\right)$, southeast $\left(112.5^{\circ}-157.5^{\circ}\right)$, south $\left(157.5^{\circ}-202.5^{\circ}\right)$, southwest $\left(202.5^{\circ}-247.5^{\circ}\right)$, west $\left(247.5^{\circ}-292.5^{\circ}\right)$, and northwest $\left(292.5^{\circ}-337.5^{\circ}\right)$. Slope direction data of the mid and late Neolithic Age sites is shown in Figure 4. 


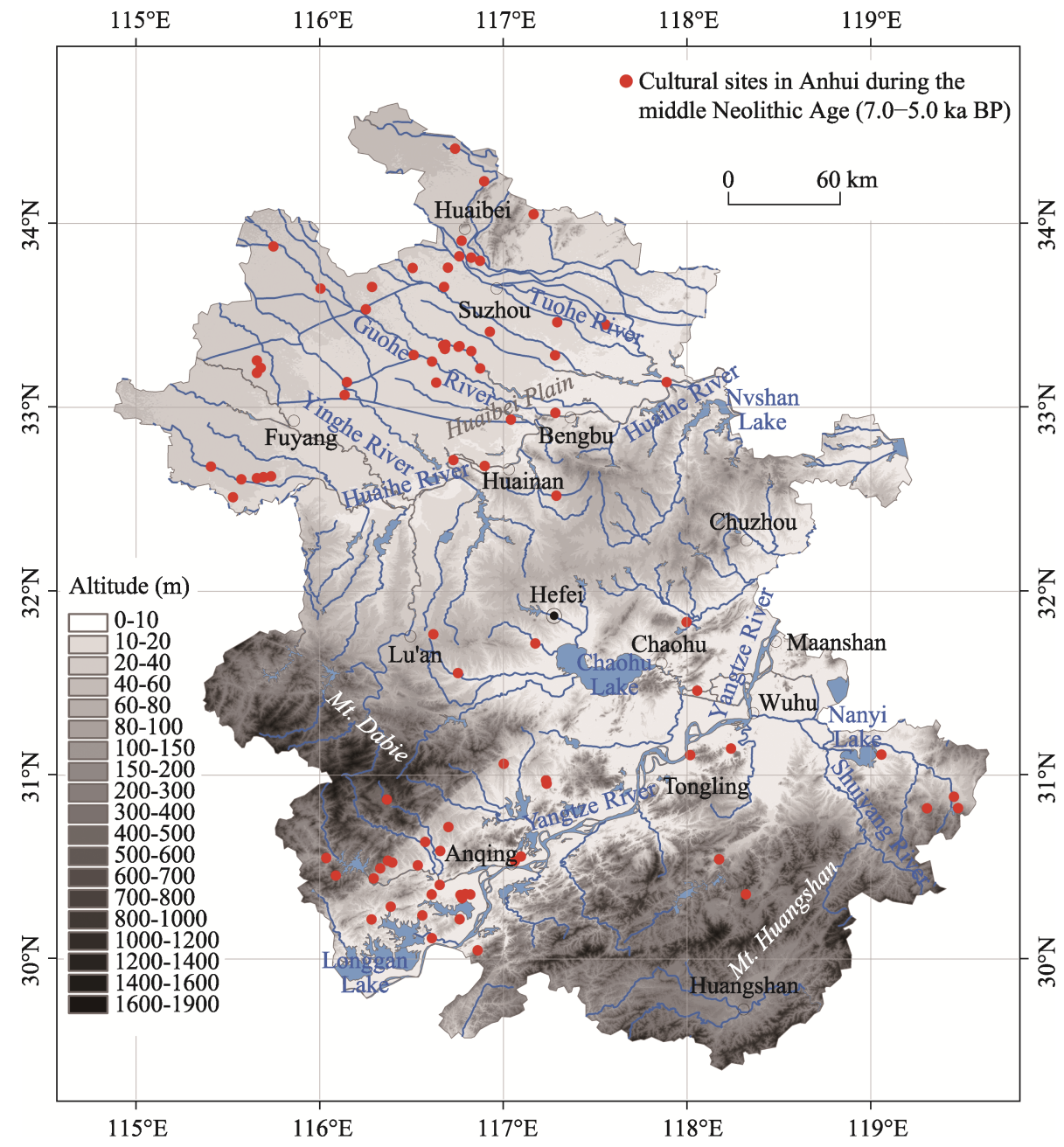

Figure 2 Distribution of cultural sites in Anhui during the middle Neolithic Age (7.0-5.0 ka BP)

Table 1 Distribution changes of Neolithic sites with altitudes during different periods in Anhui

\begin{tabular}{cccccccc}
\hline \multirow{2}{*}{ Period } & \multicolumn{6}{c}{ Changes of site distribution with different altitudes } & Total \\
\cline { 2 - 7 } & $<50 \mathrm{~m}$ & Proportion (\%) & $50-100 \mathrm{~m}$ & Proportion (\%) & $>100 \mathrm{~m}$ & Proportion (\%) & \\
\hline Early Neolithic Age & 11 & 91.7 & 0 & 0 & 1 & 8.3 & 12 \\
Mid Neolithic Age & 76 & 87.4 & 6 & 6.9 & 5 & 5.7 & 87 \\
Late Neolithic Age & 186 & 69.4 & 44 & 16.4 & 38 & 14.2 & 268 \\
\hline
\end{tabular}

By comparing the slope directions of selected sites between the mid and late Neolithic Ages (Figure 4), we were able to observe the following characteristics. In the mid Neolithic Age, the slope directions of the sites were focused on the southeast, south, north, and northeast directions, with the largest number of sites in the southeast direction and the smallest in the northwest. Such distribution characteristics are tied to the climatic environment at this time in Anhui. This area belonged to a distinct monsoon climate, where southeast wind prevailed in summer and northwest wind prevailed in winter. In order to avoid the cold northwest winter wind, our ancestors selected sunny locations that were inclined to the south to 


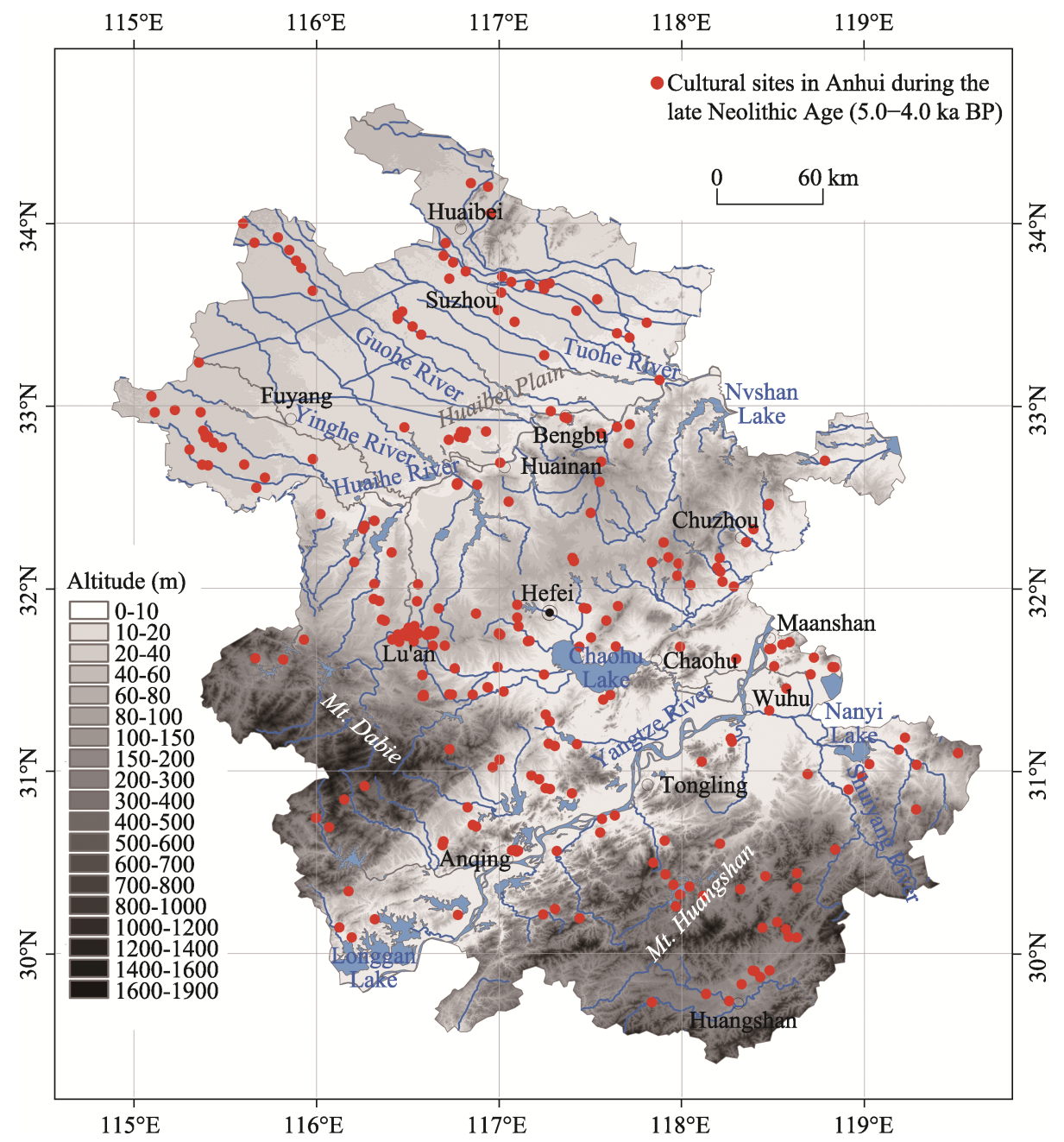

Figure 3 Distribution of cultural sites in Anhui during the late Neolithic Age (5.0-4.0 ka BP)

receive the cool from the southeast wind during the summer. In the late Neolithic Age, the number of sites inclined to the south was still the highest. Meanwhile, sites to the northwest and west were also popular, whereas the number of sites to the east, northeast, and north was the lowest. This distribution is, in part, due to the rapid increase in sites. In order to obtain more natural resources, ancient humans had to choose a location with easy access to resources, forgoing the pursuit of slope direction. In addition, this area likely had a drier climate

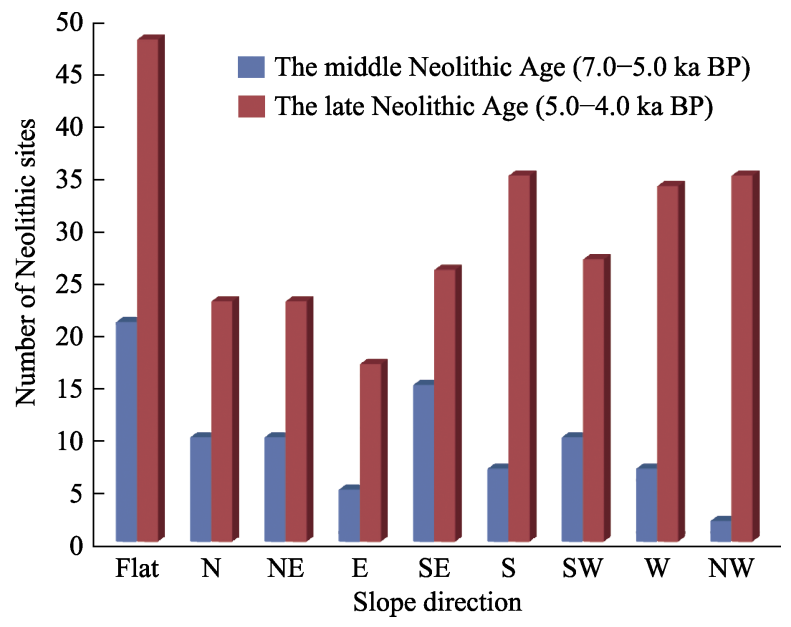

Figure 4 Distribution changes of the middle and late Neolithic sites with slope directions in Anhui 
during this period. Since the temperature was slightly higher and the sun was severe, people built their settlements in areas that were tilted away from the sun.

\subsection{Slope gradient}

Generally, human settlements were found on flat surfaces. In the mid Neolithic Age, $82.7 \%$ of the distribution of sites was within less than $2^{\circ}$, while this number was $81 \%$ in the late Neolithic Age. Meanwhile, the proportion of sites with a slope gradient more than $3^{\circ}$ was the same $(13.8 \%)$ in both the mid and late periods (Table 2). This indicates that the ancient people chose similar settlements in different periods, preferring to live in areas with small slope gradients. A possible reason for this choice was that flat terrain was widely distributed in Anhui, and they would not choose to live on mountains with great slope gradients. Instead, they chose hilly plain areas within flat terrains that had rich resources. These areas were also more conducive to communication and the development of ancient cultures.

Table 2 Distribution changes of the mid and late Neolithic sites with slope gradients in Anhui

\begin{tabular}{cccccccc}
\hline Period & Slope gradient $\left({ }^{\circ}\right)$ & 0 & $0-1$ & $1-2$ & $2-3$ & $3-4$ & $>4$ \\
\hline \multirow{2}{*}{ Mid Neolithic Age } & Site number & 21 & 40 & 11 & 3 & 3 & 9 \\
& Proportion (\%) & 24.1 & 46.0 & 12.6 & 3.5 & 3.5 & 10.3 \\
\hline \multirow{2}{*}{ Late Neolithic Age } & Site number & 48 & 116 & 53 & 14 & 6 & 31 \\
& Proportion (\%) & 17.9 & 43.3 & 19.8 & 5.2 & 2.2 & 11.6 \\
\hline
\end{tabular}

\section{Discussion}

\subsection{Characteristics of man-land relationship and cultural exchange}

The relationship between site distribution and altitude, slope direction, and slope gradient at all stages of the Neolithic Age in Anhui was generally consistent. Unlike the Yellow River Basin and many other regions in the Yangtze River Basin, there was no significant difference in the spatial characteristics of sites during different cultural periods. However, the development of human settlement sites in the Neolithic Age was not only restricted by natural conditions but also affected by regional climatic and environmental evolution factors. $\mathrm{Hu}-$ mans were accustomed to adapting to the changing trend of the environment, and therefore made adjustments to achieve the harmonious development of man-land relationship.

The environmental characteristics of the Neolithic Age in Anhui showed both similarities and differences (Table 3). By comparing research results on the environmental evolution of typical strata in five regions of Anhui (Xu et al., 1987; The No.1 HEGT and Jin, 1990; Qu et al., 1998; Yang et al., 2002; Huang et al., 2006, 2007; Ma et al., 2006; Chen et al., 2009; Wu et al., 2010, 2012b, 2015, 2019a, 2019b; Zhang et al., 2010; Xu et al., 2011; Luo et al., 2015), we found that the climate was warm and humid in the early Neolithic Age. Under these conditions, the water level of rivers and lakes rose, and marshes and wetlands were widespread. Considering this, the range of human activities was greatly limited and concentrated only in the high terrain areas to prevent the threat of natural disasters, such as floods. The number of early Neolithic sites in Anhui was small and their concentration in hilly ter- 
races was a response to this environment. Due to the scattered distribution of settlement sites, there was no evidence of a large-scale prehistoric cultural exchange (CCCAP, 1998; Sun, 2013; SACH, 2014).

Table 3 Paleoenvironmental characteristics recorded by the typical strata in Anhui

\begin{tabular}{|c|c|c|c|c|}
\hline Region & Stratigraphic profile & $\begin{array}{l}\text { Time range } \\
(\mathrm{ka} \mathrm{BP})\end{array}$ & Environmental characteristic & References \\
\hline \multirow{5}{*}{ Huaibei Plain } & \multirow{3}{*}{$\begin{array}{l}\text { Huangkou borehole } \\
\text { in Xiaoxian }\end{array}$} & $12.0-7.5$ & Warm cool but a little wetter & \multirow{3}{*}{$\begin{array}{l}\text { The No. } 1 \text { Hydrogeological } \\
\text { and Engineering Geological } \\
\text { Team of Bureau of Geology } \\
\text { and Mineral of Anhui Province } \\
\text { and Jin, 1990; Huang et al., } \\
\text { 2006; Wu et al., 2019b }\end{array}$} \\
\hline & & $7.5-5.3$ & Warm and humid & \\
\hline & & $5.3-4.0$ & Warm but a little drier & \\
\hline & \multirow{2}{*}{$\begin{array}{l}\text { Yuchisi site in } \\
\text { Mengcheng }\end{array}$} & $5.0-4.4$ & Warm and relatively wet & \multirow{2}{*}{$\begin{array}{l}\text { Ma et al., 2006; Xu et al., } \\
2011\end{array}$} \\
\hline & & $4.4-4.0$ & Tend to be dry & \\
\hline \multirow{2}{*}{$\begin{array}{l}\text { Along the Huaihe } \\
\text { River }\end{array}$} & \multirow{2}{*}{$\begin{array}{l}\text { Yuhuicun site in } \\
\text { Bengbu }\end{array}$} & $>4.5$ & Relatively wet & \multirow{2}{*}{ Zhang et al., 2010} \\
\hline & & $4.5-4.0$ & From warm-wet to dry & \\
\hline \multirow{4}{*}{ Chaohu Lake Basin } & \multirow{4}{*}{ Chaohu borehole } & $9.9-7.7$ & $\begin{array}{l}\text { Warm and relatively wet, with } \\
\text { relatively high lake-level }\end{array}$ & \multirow{4}{*}{$\begin{array}{l}\text { Chen et al., 2009; Wu et al., } \\
\text { 2010, 2012b, 2015, 2019a; } \\
\text { Luo et al., } 2015\end{array}$} \\
\hline & & $7.7-6.0$ & $\begin{array}{l}\text { Relatively warm and wet, with } \\
\text { stable high lake-level }\end{array}$ & \\
\hline & & $6.0-4.9$ & $\begin{array}{l}\text { Warm and wet, with relatively } \\
\text { high lake-level }\end{array}$ & \\
\hline & & $4.9-2.2$ & $\begin{array}{l}\text { Relatively warm and dry, with } \\
\text { low lake-level }\end{array}$ & \\
\hline \multirow{5}{*}{$\begin{array}{l}\text { Along the Yangtze } \\
\text { River }\end{array}$} & \multirow{3}{*}{ Wuhu borehole } & $9.0-6.0$ & Warm and wet & \multirow{3}{*}{ Xu et al., 1987} \\
\hline & & $6.0-5.3$ & From damp-hot to dry-cool & \\
\hline & & $5.3-4.0$ & Tend to be drought & \\
\hline & \multirow{2}{*}{ Longgan borehole } & $10.0-6.3$ & Wet & \multirow{2}{*}{$\begin{array}{l}\text { Qu et al., 1998; Yang et al., } \\
2002\end{array}$} \\
\hline & & $6.3-4.0$ & Tend to be relatively dry & \\
\hline \multirow{3}{*}{$\begin{array}{l}\text { West Anhui moun- } \\
\text { tainous area }\end{array}$} & \multirow{3}{*}{ Tiantangzhai peat } & $8.8-7.0$ & Warm and wet & \multirow{3}{*}{ Huang et al., 2007} \\
\hline & & $7.0-5.0$ & Tend to be cool and dry & \\
\hline & & $5.0-4.0$ & From warm-wet to cold-dry & \\
\hline
\end{tabular}

In the mid Neolithic Age, the overall climatic characteristics were inherited from the previous age. The environmental characteristics revealed by each typical profile showed that the climate was wet at first and then gradually became dry. During this period, the sea level in eastern China gradually dropped (Zhu et al., 2003, 2016; Wu et al., 2014a), and the livable environment of the entire region improved. Under the relatively dry climate, humans steadily began to be active during this period, and the number of settlement sites grew rapidly. Some large-scale site groups appeared, including the Lingjiatan Neolithic site group in Hanshan County (Wang et al., 2009; Wu et al., 2015). Sites located in low altitude areas increased as well, and the distribution area gradually expanded. The major cultural regions were concentrated in the Huaibei Plain, the Chaohu Lake basin, and southwest and southeast Anhui. As cultural exchange activities progressively developed, the cultural exchange channel of the Wanjiang section of the lower Yangtze River began to form and entered the de- 
velopment stage at this time (APICRA, 2004; Sun, 2013; Shuo, 2015).

In the beginning of the late Neolithic Age, some areas of Anhui still had a relatively wet climate, but generally showed the characteristics of drying. Although the climate became dry, it had not reached the level of drought. Humans could still easily get water and other resources by moving their settlements. This was the most active period of Neolithic cultural development, and the number of sites increased very quickly. Neolithic sites were distributed in all regions of Anhui, and many larger scale site groups appeared, including the Yuchisi site in Mengcheng County, and the Xuejiagang site in Qianshan County (APICRA, 2004; Ma et al., 2006; Xu et al., 2011; Wu et al., 2019b). Different types of Neolithic cultures exchanged frequently. Under the combined influence of this environmental background and social factors, such as historical economy, the development of the Wanjiang cultural exchange channel entered the mature stage (APICRA, 2004; Sun, 2013; Shuo, 2015). As seen from the site distribution, the cultural channel lines connected various cultural areas (Figure 5). These lines were restricted by the geographical environment, which was mainly reflected in the following aspects: (1) The Neolithic culture transmission path in the Huaibei Plain was affected less by geological structure and landform, and more by river distribution. Three transmission routes of the Longshan culture were distributed along the river to the south. The west route (Linquan-Funan-Huoqiu line) mainly relied on Guhe and Runhe rivers to the southeast and reached the Jianghuai area. The middle route (Bozhou-Guoyang-Mengcheng line) was distributed along the Guohe and Beifeihe rivers, while the east route (Suixi-Suzhou-Lingbi-Sixian line) was mainly along the Tuohe River to the south. (2) Cultural communication between the Huaihe River and the Chaohu Lake was greatly affected by the geological structure and geomorphology, as well as the river system. The cultural exchange between the circle centred on the Lu'an and Chaohu Lake basin relied on the Fengle-Hangbu River, and the line of Dingyuan-Feidong was greatly affected by the Haohe and Luohe rivers. (3) The southbound route of cultural exchange from the Chaohu Lake basin to the Wanjiang Plain was not obviously dependent on a river system. This could be due to a lack of distinct, consistent human migration as a result of the route being densely covered with rivers and lakes. The main route of the Liangzhu and Songze cultures entering southeast Anhui to the Wanjiang Plain existed along the Langchuan and Guxi rivers. (4) The lakes in the southwest of Anhui were dense, and the cultural communication was mainly along the Longgan Lake area and the Yangtze River into the channel of the Wanjiang section. Cultural communication in the Wanjiang cultural exchange channel was mainly through the communication of the Yangtze River. (5) The southern part of Anhui was greatly affected by the topography. Most of the sites were located along the Xin'an and Qingyi-Shuiyang rivers. Therefore, the intercultural communication relied on these two river systems. At the end of the late Neolithic Age, the environmental droughts worsened and the culture changed.

\subsection{Impacts of environmental change on the development of Neolithic culture}

Through a comprehensive analysis of the site distribution features in the early, mid, and late Neolithic Age in Anhui, and a combination of environmental evolution characteristics since $9.0 \mathrm{ka} \mathrm{BP}$, we found that the mid and late Neolithic Age flourished with cultural development. The main climatic and environmental condition of this period was a humid climate 


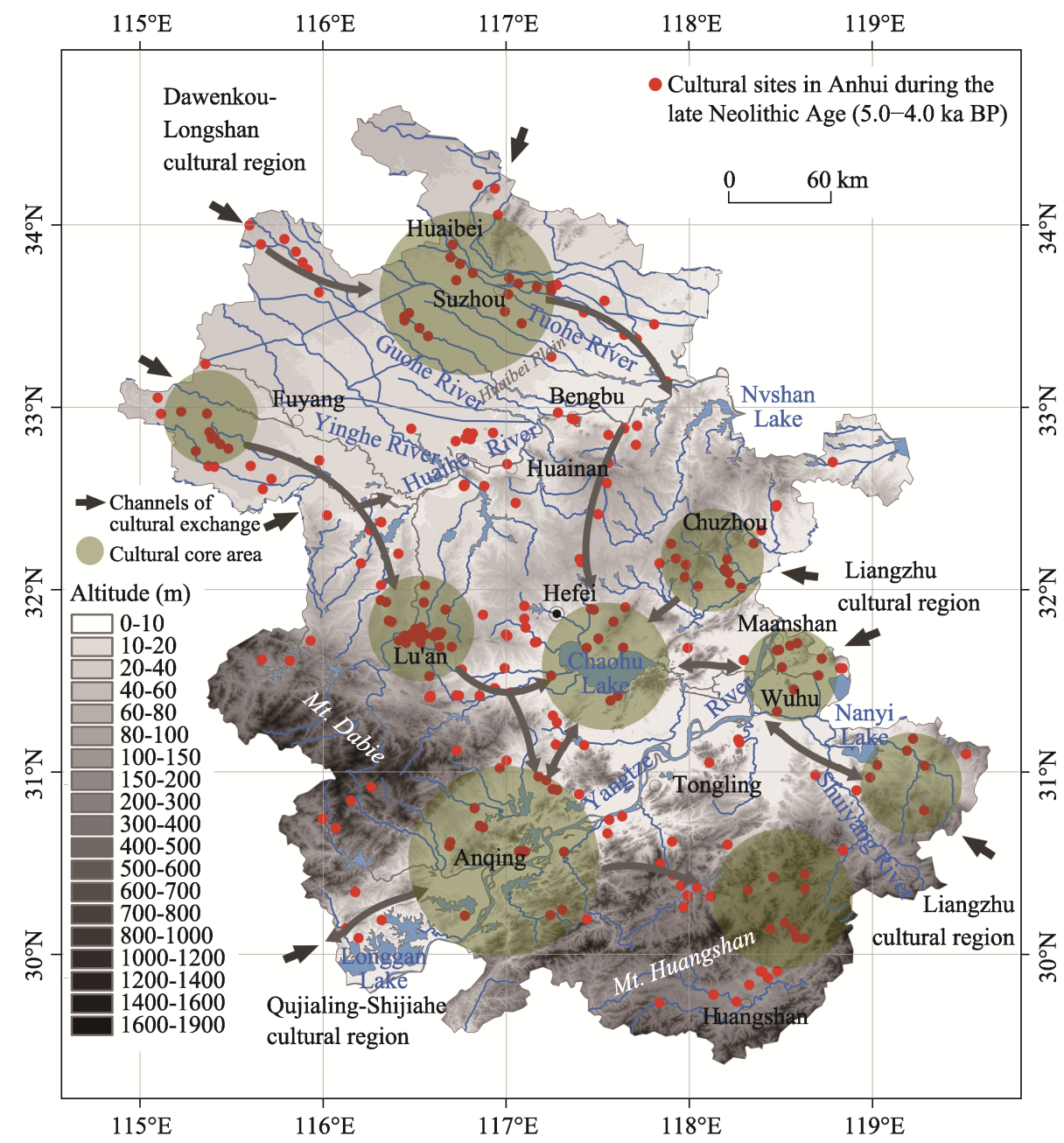

Figure 5 The Wanjiang channels of cultural exchange during the late Neolithic Age in Anhui

gradually becoming dry. This environmental background had an important impact on the development of ancient culture in this region.

Throughout the history of world civilization, the rise and fall of many early cultures was tied to climate change (Herzog, 1998; Cullen et al., 2000; Haug et al., 2003; Roberts, 2014). In Chinese civilization, the climate of the early Neolithic Age was warm and humid, and cultural development was slow. After the mid Neolithic Age, the climate began to dry and human activity gradually intensified (Chu, 1973; Wu and Liu, 2004; Mo et al., 2010; Yang et al., 2015). Zhu et al. (2003, 2016) and Wu et al. (2014a, 2014b, 2019c) analysed the spatial-temporal distribution of Neolithic sites and marine foraminifera remains of typical archaeological strata in the Yangtze River Delta and Ningshao Plain, and inferred that the warm and humid climate and high sea level before $7.0 \mathrm{ka}$ BP limited the development of human settlements. However, from 7.0 to $4.0 \mathrm{ka} \mathrm{BP}$, the climate gradually became dry and the sea level lowered. At this time, Neolithic site continuously appeared and gradually increased, leading to the development of prehistoric civilization. Although cold and dry events like ca. 5.5-5.0 ka BP also occurred during this period (Long et al., 2007; Wu et al., 2012a; 
Zhao et al., 2013), the general trend of Neolithic cultural development did not reverse. However, under the influence of the strong cold and dry events around 4.0 ka BP, China's civilization underwent significant changes (Wu and Liu, 2004; Wang et al., 2005; Liu and Feng, 2012; Wu et al., 2012a; Yuan and Han, 2013; Wu et al., 2017). Most cultures inherited from the Neolithic Age tended to die out, while the Xia Dynasty's civilization represented by the Erlitou Culture in the Central China Plains rose. Wang et al. (2015) analysed the differences in settlement evolution before and after $4.0 \mathrm{ka}$ BP in Yulin of Shaanxi and Luoyang of Henan, and the causes of paleoclimate. They found that after the $4.0 \mathrm{ka}$ BP event in the Luoyang area, precipitation was at an annual average of approximately $500 \mathrm{~mm}$. This, combined with favourable water utilization conditions and sustainable agriculture, aided to further develop settlements and culture. After this event, the average annual precipitation in Yulin area decreased to $350 \mathrm{~mm}$, and the climate transformed into a semi-arid climate. As a result, drought-farming could not be sustained and the number of settlements decreased sharply, leaving an obvious declining trend for the culture.

Based on our findings, drought can create or destroy civilizations. In the mid and late Neolithic Ages, the environmental conditions that tended to be dry often changed the previous excessive humidity, which brought convenience to the integration of culture and thus drove the development of civilization. However, once the degree of dryness exceeded a certain threshold, the resources pursued by humans were greatly reduced, and human civilization faced new challenges. At that time, the old culture would die out and a new, more appropriate culture would develop. Therefore, in the process of Chinese early civilization, humidity and drought were neither conducive nor a hinderance to the development of culture, and different cultures in different regions had different responses to environmental evolution. Under the environmental background of north and northwest China, the formation of an arid climate led to the decline of Neolithic culture by influencing water availability, social, political, and economic factors. For example, Yang et al. (2015) documented a threshold event ca. 4,200 years ago in the Hunshandake Sandy Lands of Inner Mongolia, northern China, which is associated with groundwater capture by the Xilamulun River. This process initiated a sudden and irreversible region-wide hydrologic event that exacerbated the desertification of the Hunshandake, resulting in the devastation of the Hongshan culture (6.5-3.5 ka BP, one of the important origins for Chinese civilization) (Su, 2009; Wang, 2015) and a post-Humid Period mass migration of northern China's Neolithic cultures. As for the warm-humid subtropical climate zone, 'most of them are mountains, arable land under water, wet, anaerobic and close to river', especially flat and low plains of rivers, low-lying land along rivers and coastal regions ( $\mathrm{Lu}, 2006$; Zhu et al., 2013, 2015; Wang and Wu, 2018). Therefore, a relatively dry climate environment was conducive to the development of human culture within limitations. The relationship between the cultural development of Neolithic settlement sites and the environment in Anhui reflects this man-land relationship.

\section{Conclusions}

The relationship between site distribution and environmental elements (i.e. altitude, slope direction, and slope gradient) at all stages of the Neolithic Age in Anhui was generally consistent, and there was no significant difference in the spatial characteristics of site distribution in different cultural periods. The settlement sites in Anhui were mainly distributed in 
flat, low-lying plains with an altitude below $50 \mathrm{~m}$, and the slope direction was predominantly south-southeast. More than $80 \%$ of the sites were distributed in areas with a slope gradient less than $2^{\circ}$.

The number of early Neolithic sites in Anhui was small and concentrated in a certain region, with an overall scattered distribution. At this time, there was no evidence of cultural exchanges with other provinces. The environmental characteristics of various regions in the province indicated that the climate was warm and humid, and water bodies were widely distributed. By the mid Neolithic Age, the number of sites had increased rapidly with a wide distribution area. The main cultural areas were concentrated in the Huaibei Plain, southwest and southeast Anhui, and around the Chaohu Lake line, while the development of other areas remained slow and scattered. During this period, the climate began to change from warm-wet to warm-dry, and cultural exchange activities gradually developed. In the late Neolithic Age, the number and distribution of sites reached their peak. The climate was relatively dry, but humans could still obtain water and other resources by moving their settlements. The suitable climate and environment made communication between different Neolithic cultures very prosperous. The ancient settlements and cultural development increased, and the Wanjiang cultural exchange channel developed, entering a mature stage.

In the early civilization development, cultures in different regions had different responses to environmental changes. In subtropical areas with a warm and humid climate, especially low-lying river and lake plains, and low-lying areas along rivers and coastal areas, a relatively dry climate environment was conducive to the development of human culture. The distribution and evolution of Neolithic sites and the relationship between cultural development and the environment in Anhui reflects this man-land relationship.

\section{Acknowledgments}

Special thanks to Chuan Wang, Wenpeng Zhao, and Haiping Yu for their support and help with the field investigation and manuscript editing.

\section{References}

Anhui Provincial Institute of Cultural Relics and Archaeology (APICRA), 2004. Xuejiagang Site in Qianshan. Beijing: Cultural Relics Press. (in Chinese)

Chen F H, Dong G H, Zhang D J et al., 2015. Agriculture facilitated permanent human occupation of the Tibetan Plateau after 3600 B.P. Science, 347: 248-250.

Chen W, Wang W M, Dai X R, 2009. Holocene vegetation history with implications of human impact in the Lake Chaohu area, Anhui Province, East China. Vegetation History and Archaeobotany, 18(2): 137-146.

Chen Z Y, Zong Y Q, Wang Z H et al., 2008. Migration patterns of Neolithic settlements on the abandoned Yellow and Yangtze River deltas of China. Quaternary Research, 70(2): 301-314.

Chorography Compiling Commission of Anhui Province (CCCAP), 1998. Anhui Chorography Relics. Beijing: Chronicles Press. (in Chinese)

Chorography Compiling Commission of Anhui Province (CCCAP), 1999. Anhui Chorography Natural Environment. Beijing: Chronicles Press. (in Chinese)

Chu K C, 1973. A preliminary study on the climatic fluctuations during the last 5,000 years in China. Science China: Mathematics, 16(2): 226-256.

Cullen H M, deMenocal P B, Hemming S et al., 2000. Climate change and the collapse of the Akkadian empire: Evidence from the deep sea. Geology, 28(4): 379-382. 
Deng H, Chen Y Y, Jia J Y et al., 2009. Distribution patterns of the ancient cultural sites in the middle reaches of the Yangtze River since 8500 a BP. Acta Geographica Sinica, 64(9): 1113-1125. (in Chinese)

Dong G H, Jia X, Elston R et al., 2013. Spatial and temporal variety of prehistoric human settlement and its influencing factors in the upper Yellow River valley, Qinghai Province, China. Journal of Archaeological Science, 40: 2538-2546.

Dutt S, Gupta A K, Singh M et al., 2019. Climate variability and evolution of the Indus civilization. Quaternary International, 507: 15-23.

Fu B J, Pan N Q, 2016. Integrated studies of physical geography in China: Review and prospects. Journal of Geographical Sciences, 26(7): 771-790.

Guo Y Y, Mo D W, Mao L J et al., 2013. Settlement distribution and its relationship with environmental changes from the Neolithic to Shang-Zhou dynasties in northern Shandong, China. Journal of Geographical Sciences, 23(4): 679-694.

Haggett P, 1965. Locational Analysis in Human Geography. London: Edward Arnold.

Haug G H, Günther D, Peterson L C et al., 2003. Climate and the collapse of Maya civilization. Science, 299: $1731-1735$.

Herzog R, 1998. Staaten der Frühzeit: Ursprünge und Herrschaftsformen. Beijing: Peking University Press.

Huang R, Zhu C, Guan Y et al., 2006. Impact of Holocene environmental change on temporal-spatial distribution of Neolithic sites in Huaihe River Basin, Anhui Province. Journal of Geographical Sciences, 16(2): 199-208.

Huang R, Zhu C, Wang S T, 2007. Magnetic susceptibility and Rb/Sr ratio of peat stratum in Tiantangzhai and its significance of palaeoclimate. Scientia Geographica Sinica, 27(3): 385-389. (in Chinese)

Institute of Geologic Surveying and Mapping, Anhui Province (IGSMAP), 2017. Atlas of Mineral Resources and Geological Environment in Anhui Province. Beijing: SinoMaps Press. (in Chinese)

IPCC Core Writing Team, 2014. Climate Change 2014: Synthesis Report. Contribution of Working Groups I, II and III to the Fifth Assessment Report of the Intergovernmental Panel on Climate Change. Geneva, IPCC.

Leng S Y et al., 2017. The Geographical Sciences during 1986-2015: From the Classics to the Frontiers. Singapore: Springer.

Li F, Wu L, Zhu C et al., 2013. Spatial-temporal distribution and geographic context of Neolithic cultural sites in the Hanjiang River Basin, southern Shaanxi, China. Journal of Archaeological Science, 40: 3141-3152.

Li J J, Zhang W P, He J, 2010. Rivers and Lakes of Anhui. Wuhan: Changjiang Publishing House. (in Chinese)

Li Z X, Zhu C, Wu G X et al., 2015. Spatial pattern and temporal trend of prehistoric human sites and its driving factors in Henan Province, Central China. Journal of Geographical Sciences, 25(9): 1109-1121.

Liu F G, Feng Z D, 2012. A dramatic climatic transition at 4000 cal. yr BP and its cultural responses in Chinese cultural domains. The Holocene, 22(10): 1181-1197.

Long H, Wang N A, Li Y et al., 2007. Mid-Holocene climate variations from lake records of the East Asian monsoon margin: A multi-proxy and geomorphological study. Quaternary Sciences, 27(3): 371-381. (in Chinese)

Lu J Y et al., 1992. Seismic Structure and Environmental Analysis in Anhui Province. Hefei: Anhui Science and Technology Publishing House. (in Chinese)

Lu P, Chen P P, Tian Y et al., 2019. Reconstructing settlement evolution from Neolithic to Shang Dynasty in Songshan mountain area of central China based on self-organizing feature map. Journal of Cultural Heritage, 36: 23-31.

Lu Y C, 2006. Analysis of structure characteristics and driving factors of development of WeiTian in Southeastern Anhui Province based on Landsat TM data [D]. Wuhu: Anhui Normal University. (in Chinese)

Luo W H, Zhang J Z, Yang Y Z et al., 2015. Late Pleistocene-middle Holocene environmental evolution: Phytolith record from the lacustrine deposits of the Chaohu Lake, Anhui. Acta Micropalaeontologica Sinica, 32(1): 63-74. (in Chinese)

Ma C M, Zhu C, Zhu G Y et al., 2006. Magnetic susceptibility and elemental geochemistry analysis of the archaeological strata at the Yuchisi site, Anhui. Journal of Stratigraphy, 30(2): 124-130. (in Chinese)

Mo D W, Zhao Z J, Xu JJ et al., 2010. Holocene environmental changes and the evolution of the Neolithic cultures in China. Landscapes and Societies, doi: 10.1007/978-90-481-9413-1_19.

National Research Council (NRC), 2010. Understanding the Changing Planet: Strategic Directions for the Geographical Sciences. USA: National Academies Press. 
Putzer A, Festi D, Edlmair S et al., 2016. The development of human activity in the high altitudes of the Schnals Valley (South Tyrol/Italy) from the Mesolithic to modern periods. Journal of Archaeological Science: Reports, 6: $136-147$.

Qu W C, Wu R J, Yang X D et al., 1998. The palaeoenvironmental and palaeoclimatic changes of Longgan Lake since the past 3000 years. Journal of Lake Sciences, 10(2): 37-43. (in Chinese)

Redman C L, James S R, Fish P R et al., 2004. The Archaeology of Global Change: The Impact of Humans on Their Environment. Washington, USA: Smithsonian Books.

Roberts N, 2014. The Holocene: An Environmental History. 3rd ed. Chichester, UK: Wiley Blackwell.

Schirrmacher J, Kneisel J, Knitter D et al., 2020. Spatial patterns of temperature, precipitation, and settlement dynamics on the Iberian Peninsula during the Chalcolithic and the Bronze Age. Quaternary Science Reviews, 233: 106220 .

Shuo Z, 2015. Settlements and cultures in the Wanjiang River basin during the Songze cultural period. Southeast Culture, (1): 66-78. (in Chinese)

State Administration of Cultural Heritage (SACH), 2014. An Atlas of Chinese Cultural Relics · Anhui. Beijing: SinoMaps Press. (in Chinese)

Su B Q, 2008. Chinese Archaeological Integration: East China Volume I. Zhengzhou: Zhongzhou Ancient Books Publishing House. (in Chinese)

Su B Q, 2009. New Investigation on the Origin of Chinese Civilization. Shenyang: Liaoning People's Publishing House. (in Chinese)

Sun W, 2013. The relationship between the cultural channel of Neolithic sites and the geographical environment in Anhui Province [D]. Nanjing: Nanjing University. (in Chinese)

The No.1 Hydrogeological and Engineering Geological Team of Bureau of Geology and Mineral of Anhui Province (No.1 HEGT), Jin Q, 1990. Quaternary System of Huaibei Plain in Anhui. Beijing: Geological Publishing House. (in Chinese)

Trigger B G, 1967. Settlement archaeology: Its goals and promise. American Antiquity, 32(2): 149-160.

Wagner M, Tarasov P, Hosner D et al., 2013. Mapping of the spatial and temporal distribution of archaeological sites of northern China during the Neolithic and Bronze Age. Quaternary International, 290/291: 344-357.

Wang F, Yang Z P, Luan F M et al., 2015. Spatiotemporal characteristics of cultural sites and their driving forces in the Ili River Valley during historical periods. Journal of Geographical Sciences, 25(9): 1089-1108.

Wang W, 2015. Dictionary of Chinese Archaeology. Shanghai: Shanghai Lexicographical Publishing House. (in Chinese)

Wang X Y, Guo Z Y, Wu L et al., 2012. Extraction of palaeochannel information from remote sensing imagery in the east of Chaohu Lake, China. Frontiers of Earth Science, 6(1): 75-82.

Wang X Y, Wu L, 2018. Geological Investigation and Regional Geological Tourism in the North Mountain of Chaohu Lake. Hefei: University of Science and Technology of China Press. (in Chinese)

Wang X Y, Wu L, Wu X Z et al., 2009. Geographical environment characteristics of ancient human activities in the Lingjiatan Site of Chaohu City, Anhui Province, China. Geographical Research, 28(5): 1208-1216. (in Chinese)

Wang Y J, Cheng H, Edwards R L et al., 2005. The Holocene Asian monsoon: Links to solar changes and North Atlantic climate. Science, 308: 854-857.

Weiberg E, Unkel I, Kouli K et al., 2016. The socio-environmental history of the Peloponnese during the Holocene: Towards an integrated understanding of the past. Quaternary Science Reviews, 136: 40-65.

Willey G R, 1953. Prehistoric Settlement Patterns in the Viru Valley, Peru. In: Bulletin 155. Smithsonian Institution: Bureau of American Ethnology.

Wu L, Li F, Zhu C et al., 2012a. Holocene environmental change and archaeology, Yangtze River Valley, China: Review and prospects. Geoscience Frontiers, 3(6): 875-892.

$\mathrm{Wu}$ L, Li L Y, Zhou H et al., 2019a. Holocene fire in relation to environmental change and human activity reconstructed from sedimentary charcoal of Chaohu Lake, East China. Quaternary International, 507: 62-73.

Wu L, Wang X Y, Gao F, 2016. An integrated approach for the detection of small archaeological sites along palaeochannels: A case study in the Northeast Chaohu area, China. Journal of Archaeological Science: Reports, 6: 434-441.

Wu L, Wang X Y, Mo D W et al., 2015. Elemental geochemistry of the Lingjiatan site in Hanshan, East Chaohu Lake Basin. Journal of Stratigraphy, 39(4): 443-453. (in Chinese) 
Wu L, Wang X Y, Zhou K S et al., 2010. Transmutation of ancient settlements and environmental changes between 6000-2000 aBP in the Chaohu Lake Basin, East China. Journal of Geographical Sciences, 20(5): $687-700$.

Wu L, Wang X Y, Zhu C et al., 2012b. Ancient culture decline after the Han Dynasty in the Chaohu Lake Basin, East China: A geoarchaeological perspective. Quaternary International, 275: 23-29.

Wu L, Zhou H, Li J Y et al., 2019b. Thiessen polygon analysis and spatial pattern evolution of Neolithic cultural sites (8.0-4.0 ka BP) in Huaibei Plain of Anhui, East China. Quaternary International, 521: 75-84.

Wu L, Zhu C, Ma C M et al., 2019c. Sedimentary environment recorded by microfossils from the strata of the Taozhuang Neolithic site in Xinghua, Jiangsu Province, China. Acta Geologica Sinica (English Edition), 93(supp.2): 280-281.

Wu L, Zhu C, Li F et al., 2018. Environmental Archaeology of the Mid-Holocene Palaeofloods in the Jianghan Plain, Central China. Beijing: Science Press. (in Chinese)

Wu L, Zhu C, Ma C M et al., 2017. Mid-Holocene palaeoflood events recorded at the Zhongqiao Neolithic cultural site in the Jianghan Plain, middle Yangtze River Valley, China. Quaternary Science Reviews, 173: $145-160$.

Wu L, Zhu C, Zheng C G et al., 2014a. Holocene environmental change and its impacts on human settlement in the Shanghai Area, East China. Catena, 114: 78-89.

Wu L, Zhu C, Zheng C G et al., 2014b. Impact of Holocene climate on the prehistoric cultures of Zhejiang region, East China. Journal of Geographical Sciences, 24(4): 669-688.

Wu W X, Liu T S, 2004. Possible role of the "Holocene Event 3" on the collapse of Neolithic Cultures around the Central Plain of China. Quaternary International, 117: 153-166.

Xu L B, Sun L G, Wang Y H et al., 2011. Prehistoric culture, climate and agriculture at Yuchisi, Anhui Province, China. Archaeometry, 53(2): 396-410.

$\mathrm{Xu}$ X, Zhang S W, Zhou S, 1987. A preliminary study of the vegetation, climate and environment from Wuhu to Jiangyin region since 30000 years B.P. Journal of Nanjing University (Natural Sciences Edition), 23(3): 556-574. (in Chinese)

Yang X D, Wu Y H, Zhu Y X et al., 2002. Environmental changes revealed by lacustrine sediment from Longgan Lake since Last Glacial Maximum. Journal of Lake Sciences, 14(2): 106-110. (in Chinese)

Yang X P, Scuderi L A, Wang X L et al., 2015. Groundwater sapping as the cause of irreversible desertification of Hunshandake Sandy Lands, Inner Mongolia, northern China. Proceedings of the National Academy of Sciences of the United States of America, 112(3): 702-706.

Yuan W W, Han M L, 2013. The explanation on the selection of settlements and environment in Haidong Prefecture, Qinghai Province during the mid-Holocene. Geographical Research, 32(5): 942-951. (in Chinese)

Zhang G S, Zhu C, Wang J H et al., 2010. Environmental archaeology on Longshan Culture (4500-4000 aBP) at Yuhuicun Site in Bengbu, Anhui Province. Journal of Geographical Sciences, 20(3): 455-468.

Zhang Z H, 2004. Neolithic Archaeology of China. Nanjing: Nanjing University Press. (in Chinese)

Zhao C S P, Mo D W, 2020. Holocene hydro-environmental evolution and its impacts on human occupation in Jianghan-Dongting Basin, middle reaches of the Yangtze River, China. Journal of Geographical Sciences, 30(3): 423-438.

Zhao G Y, Liu X M, Chen Q et al., 2013. Paleoclimatic evolution of Holocene loess and discussion of the sensitivity of magnetic susceptibility and median diameter. Quaternary International, 296: 160-167.

Zhu C, Li L, Liu W Q et al., 2013. An Introduction to Environmental Archaeology. Beijing: Science Press. (in Chinese)

Zhu C, Wu L, Li L et al., 2016. Recognition of sea-level change during the Neolithic period in the Jiangsu Area, East China. Chinese Science Bulletin, 61(3): 374-387. (in Chinese)

Zhu C, Zheng C G, Ma C M et al., 2003. On the Holocene sea-level highstand along the Yangtze Delta and Ningshao Plain, East China. Chinese Science Bulletin, 48(24): 2672-2683.

Zhu C, Zheng C G, Wu L et al., 2015. Environmental Archaeology since the Neolithic Age in the Yangtze River Valley, China. Beijing: Science Press. (in Chinese)

Zhu G Y, Zhu C, Ling S J et al., 2005. Spatial-temporal distribution of Neolithic and Xia-Shang-Zhou dynasties sites and relationship between human and environment in Anhui Province. Scientia Geographica Sinica, 25(3): 346-352. (in Chinese) 